\title{
Combating Human Trafficking: Tactical Features of the Purpose and Execution of Forensic Examination
}

\author{
Alexey Vladimirovich, Boretsky \\ Guldana Anuarbekovna, Abenova \\ Zhanna Kabidenovna, Azhibaeva \\ Aynash Kartabaevna, Kydralinova \\ Nauryzkhan Terlikbaevich, Sanasyrov
}

Department of "Jurisprudence", Innovative University of Eurasia, Kazakhstan, 140000, Pavlodar, M. Gorky Street, 102/4

Email: alexey1977.77@mail.ru

Doi:10.5901/mjss.2014.v5n23p565

\begin{abstract}
In the present study, the authors considered the features of forensic examinations execution in the investigation of crimes related to human trafficking in the Republic of Kazakhstan. In the study, the authors regarded the most common types of forensic examinations, usually conducted in criminal cases of trafficking. The paper offers practical recommendations for criminal prosecution bodies on the most effective forensic examinations in criminal cases of the category, based on an analysis of the scientific literature, as well as the survey of practitioners engaged in combating human trafficking and the analysis of criminal cases involving human trafficking.
\end{abstract}

Keywords: human trafficking, forensics, investigation of crimes, combating trafficking in persons, special expertise.

\section{Introduction}

Unfortunately, socio-economic processes of the last decades are accompanied by criminalization of society, growth and modification of the structure of crime in the Republic of Kazakhstan. There, increasingly important place, occupy activities of organized, technically equipped criminal groups, having considerable resource base, which significantly complicates the detection and investigation of crimes, causes increase of the role of expert knowledge in proving and especially the basic procedural form of their application - forensics.

Investigation of human trafficking, as a rule, is a rather complex process, since criminal activity on human trafficking, in most cases, is characterized by a high level of organization, good technical equipment, which in turn, causes difficulties in the subject of the investigation. These factors, in most cases, determine the need to use the expert knowledge in the detection and investigation of the facts of human trafficking. When investigating these crimes, the assignment and production of expertise is among the urgent investigative actions, as the results of the examination in many cases may be the most important evidence in proving the guilt of the perpetrators.

Appointment and execution of expertise are provided in Chapter 32 of the Criminal Procedure Code of the Republic of Kazakhstan (Articles 240-255) (1997).

Previously, the use of expert knowledge in the detection and investigation of crimes, including trafficking in human beings, have been considered by such authors as: W.W. Bennett and K.M. Hess (2006), N. Tilley and A. Ford (1996), J. Nickell and J.F. Fischer (2014), C. McCartney (2013), I. Pepper (2010), G. Laycock (2004), C. Roux, F. Crispino and O. Ribaux (2012), J.W. Bond and L. Sheridan (2008), A.V. Boretsky and S.K. Zhetpisov (2013), A.Y. Ginsburg, G.I. Povreznyuk and B.A. Salaev (1998), G.A. Elenyuk (2001), and others. However, despite the fact that common issues of using forensic examinations opportunities in the detection and investigation of crimes are sufficiently studied, the research of forensic examinations during the human trafficking investigation are still inadequate and require further exploration. 


\section{Research Methods}

Methodological bases of this study were the dialectical method of knowledge of socio-legal phenomena, as well as systematic-structural, comparative legal, logical-theoretical and special scientific study methods. In addition, in the work were used such sociological techniques as questionnaires and interviewing of law enforcement personnel (a total of 150 investigators and detective personnel were surveyed and interviewed). To achieve objectivity of the research results, these methods have been applied comprehensively.

\section{Results and Discussion}

According to results of the scientific literature analysis; the survey of investigators and investigative staff of the Ministry of Internal Affairs of the Republic of Kazakhstan; as well as the study of criminal trafficking cases, investigated in the Republic of Kazakhstan, the following objects of forensic examinations in criminal cases, related to human trafficking must be identified:

- living people (and possibly corpses of stolen, sold and previously exploited persons);

- objects with traces of fingers and biological objects;

- different kinds of draft records and documents;

- audio and video recordings, photographs.

Depending on the mechanism of criminal activity, the range of the objects can be expanded.

According to interviews with representatives of the investigation involved in the inquiry of trafficking (Diagram 1), among the most frequently encountered during the detection of criminal cases of this category should be included the following types of forensic examinations:

- medical examination;

- biological expertise;

- handwriting analysis;

- phonoscope examination;

- scent evidence analysis;

- others.

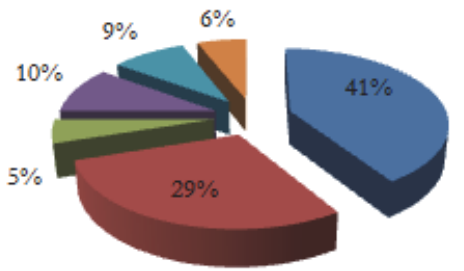

$$
\begin{aligned}
& \text { "I medical examination } \quad \text { I biological expertise }
\end{aligned}
$$

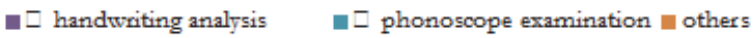

\section{Diagram 1}

Forensic examination. This expertise gives opinions on questions of medical and biological nature. In relation to the investigation of criminal cases of this category its tasks will include:

- Examination of the found corpses of trafficking victims;

- Examination of the victims to determine the nature and severity of the bodily and health harm, age of minors and juvenile victims;

- $\quad$ Examination of physical evidence through the laboratory tests.

In the course of a corpse examination, the answers to questions about the time and cause of death are clarified. In case of a decision on the qualifying difference or additional qualification of actions of the subjects, it may be necessary to clarify the question about the main cause of death. It could come from the injuries that have been caused to the victim by the dealer or the exploiter, but could also be caused by a disease.

In case of available evidence of abuse and violence against the victims and detection of a corpse, it is ascertained:

- When the death occurred? 
- Whether it is possible to assume that the death occurred at a certain time and if so, under what signs?

- What is the cause of death?

- What was the main cause of death - trauma or illness?

- What damage was detected on the corpse, what is its nature, location, and what it could have been caused by?

- What damage was inflicted during his life and what after his death?

- What is the sequence of injury?

- What kind of damage was the cause of death?

- If each of the multiple injuries individually could not cause the death of the victim, then was it caused by all the damage in the aggregate or not?

- Whether there is a direct causal link between the resulting injuries and death of the victim?

- Whether the death occurred immediately after the damage has been inflicted or in a certain period?

- Whether the medical records on the localization, nature and characteristics of damage established in the examination of the corpse, correspond to the testimony of the accused, the suspect (or witness) of the type of injury that led to the death of the victim? (Teaching aid for appointing examinations, 2003).

In case if the accused denies contact with the victim body in the place of discovery and refers to the random arrival of the injured person and his request for assistance, the expert should be questioned whether the place the body was discovered and the damage, identified during the inspection corpse had been inflicted, is the same. To some extent, this question can be answered by crime scene examination, conducted in order to detect signs of struggle, and other signs of a long-term presence of the victim in the place where, according to the accused, it appeared randomly.

The victim's examination allows defining the nature and severity of the inflicted bodily injuries, the degree of exhaustion and loss of labour ability as the exploitation result, as well as the age of the trafficking victim. Expert conclusion on the nature and severity of the damage, the depletion of the victim and the loss of labour ability "reinforces" the testimony given during questioning of the victim and the results of examination in the charges materials.

Necessity to clarify the age of the victim may arise in the absence of the documents and witnesses who would describe its age accurately enough.

Dimensions of persistent disability in case of damage are set based on objective evidence and possible consequences of the damage, also taking into account the table of disability percent. Persistent disability at disabled persons is defined the same way as in practically healthy people, regardless of disability and its group.

Forensic expert must determinate:

- presence and nature of the damage;

- distinction in prescription of a bodily harm infliction

- weapons and features of the method of injury infliction (medical data). Under the methods of injury infliction are meant:

- activity which causes suffering by prolonged deprivation of food, drink, or warmth, either placing or leaving the victim in unhealthy conditions, or other similar actions (torture);

- activities, connected with repeated or prolonged infliction of pain - tweaking, cutting, causing multiple but minor injuries with blunt or sharp objects, exposure to thermal factors, and other similar actions (torture) (Investigator's directory. Applied Criminology, 1992).

The main issues that the expert should determine include:

1. Is there any damage in the person (victim), if so, what is their nature, number and location?

2. What weapons and means could have cause the damage?

3. What is the mechanism of the injury, prescription (period) of its (their) infliction?

4. What is the severity of the bodily harm, specifying the qualifying sign (danger to life, health disorder, persistent disability, etc.)?

5. What instrument (weapon) or object and how exactly was inflicted the damage to the victim? Could it be caused by the present instrument (weapon), subject?

6. Could the injuries found at the victim have been inflicted under specific circumstances and conditions, which shows the victim (the nature of weapon, the mutual position of the persons at the time of injury, etc.)?

7. Whether the testimony of a victim corresponds to objective evidence about a particular way of damage and instrument (weapon) or object that the damage was caused with?

8. Was the damage inflicted to the victim at the same or a different time?

9. Could the injuries (damage) have been caused with the victim's own hand?

10. What is the gravity of the bodily damage in the given person? 
11. What is the size of permanent loss of general ability to work of the victim?

12. What are possible consequences of this damage? A forensic pathologist with involvement of appropriate medical expert (ophthalmologist, otolaryngologist etc) solves this question.

Forensic biological examination. Objects of this type of research under this category of criminal cases are objects with traces of blood, semen, saliva and hair, urine, feces.

Biological expertise allows to define identity of blood, semen, saliva, hair. This proves that others committed certain actions, such as sexual relations in the apartment of the accused. Presence of large numbers of cigarette butts with traces of saliva of the victims in the basement, isolated room with a lock, etc. supports the victim testimony that they were kept in this particular area.

In conjunction with the testimony of the victims, the arrest and search results are proof of sexual or other exploitation, presence of the victims on the object of inspection or search in cramped and unsanitary conditions.

Results of the samples study (traces on the ground, on the floor) in the district (in the place) of confinement of trafficking victims and use of their slave labor would indicate that the victims were kept without any basic amenities. Along with other evidence, the expert opinion will also be proof of implementation against one or more victims of authority inherent in the right of ownership, i.e. the disposal of a person, excluding his basic physiological needs.

The issues that are resolved by this expertise include:

- Is any blood, semen, or saliva present on the adduced objects?

- What is the group affiliation of objects (blood, saliva, semen, etc.)?

- what is the mechanism of formation of traces?

- whether the blood belongs to a particular person?

- Are there any traces of saliva, semen, urine on the objects presented for examination?

- Do the discharges belong to a specific person?

- What is the period of limitation of blood stains?

- Was the stain formed by blood of a living person or a corpse?

- What is the group affiliation of adipose traces?

- who left traces of lips, male or female?

- Whether they were left by specific person? (Instruction on the procedure of forensic examinations, 1981).

Handwriting examination. Studying manuscripts and separate records is held to establish their writers. In aggregate the results of handwriting contents' inspection and their place of detection the outcome of expert handwriting analysis can be the proof:

- the "entertainment" company manager keeping registration book of sexual services;

- prostitute's personal records of clients, receiving minor sums of money for expences, personal impressions of sexual exploitation;

- signing a void contract of employment, for example, abroad, between the accused and the victim;

- the accused giving written orders to his subordinates on the regime of detention of victims of trafficking and exploitation;

- payments between subjects for sold victims;

- actual possession by the defendant of the appartments where the victims were exploited sexually or temporary concealed;

- the accused getting tickets, vouchers and other documents for transportation of victims in another region or abroad.

The main task of expert handwriting analysis - establishing the author of a handwriting or signature. Besides the test document, samples for comparison are sent for examination, which are divided into free, conditionally free and experimental (Instruction on the procedure of forensic examinations, 1981).

Questions to an expert are as follows:

1. A person of which gender has written the document submitted to the study?

2. One or different persons are authors of the studied texts?

3. Whether the text is suitable for identification research?

4. Was the text's handwriting intentionally altered?

5. Whether the text has been executed (signed) with imitation (signature) of a particular person?

6. Was the manuscript (signature) written with unusual for the artist writing instrument?

7. Whether the text (signature) has been executed by someone whose handwriting samples are present in the study? (Elenyuk G.A., 2001).

Phonoscope examination. Conducting this examination allows you to "attach" the meaning of the conversation 
and some phrases to specific suspect (accused). The main objective of the research on this category of cases concerns the identification of persons on the grounds of speech, which are reflected in certain acoustic and linguistic characteristics.

The phonoscopic examination is assigned for audio or video recordings of telephone conversations of defendants, their personal meetings, records held during rapid examination, test buy and operational experiment. In the course of inspection and listening to the magnetic recording those speech areas of the suspected (accused) are highlighted, which contain the phrases and individual expressions of evidentiary value.

Question to the expert can be formulated as follows:

1. How many people participated in the conversation, fixed on a phonogram provided?

2. What was the environment at the time of recording the provided track?

3. Whether the speech fixed in a phonogram belongs to a particular person?

4. Which person each fragment of the recording belongs to?

5. Whether the suspect or other person uttered certain phrases (literally identifies key phrases that indicate the preparation and implementation of a criminal plan aimed at human trafficking and slave labor)?

6. What is the content of illegible entries submitted on a phonogram?

7. What are the sources of non-speech sounds recorded on a phonogram provided? Are there on this tape recorded sounds of specific objects (an animal, a car, a telephone, or other technological or biological object)?

Scent evidence analysis. The items left in place of concealment and (or) exploitation that allegedly belonged to the suspect (accused) can be the objects of this examination. These objects may include, for example, clothing, footwear, headgear, gloves, personal belongings (purse, notebook, folder, organizer, bag, etc.).

The main tasks of forensic scent evidence analysis is establishing the identity of the suspect (accused) in trafficking and (or) the use of slave labor by the smell they left. One of the peculiarities of these expert studies is that they usually end with giving explicit conclusions about the absence of identity by the smell and conclusions about the alleged presence of such identity.

Certain evidentiary value may have scent sample, which is carried out using several dogs who consistently work out to "expertise".

Depending on circumstances of the criminal activity mechanism under investigation and the available evidentiary information, contained on different objects, it is possible to conduct other examinations (identification studies) that will form the evidentiary basis of the criminal case.

For example, in case of detection of photos or videos, where the accused has been recorded next to the victim, in place of concealment or exploitation, an examination for personal identification using photographs or videos is possible.

During the investigation there can be detected a video or digital surveillance system recording where it is fixed, that the defendant enters the room, which was used for recruitment, concealment, or exploitation of victims of human trafficking and slave labor. In this case, identification of individuals by use of these materials is available as well, especially on condition that the suspect (accused) has been detained or arrested.

\section{Conclusions}

In the present study, the authors have considered only the most common types of forensic examinations, which are usually appointed for investigating the facts of human trafficking. In each case, taking into account the features and characteristics of the criminal case and investigation, other forensic examinations can be assigned and performed.

The study suggests the following conclusions:

Using forensic examinations for investigating the facts of human trafficking is essential for detection and investigation of these crimes; examination;

The subject of the investigation must thoroughly understand the tactical features of the production of certain judicial

The authors' research and practical recommendations on the appointment and conduct of the forensic examinations analyzed in the study, are essential for the successful investigation of the facts of human trafficking, but at the same time they are of advisory value and may be adapted taking into account the peculiarities of the criminal case.

\section{References}

Bennett, W.W., Hess, K.M. (2006).Criminal investigation. Cengage Learning.

Bond, J.W., Sheridan, L. (2008). A novel approach to maximising the detection of volume crime with DNA and fingerprints. International 
Journal of Police Science and Management, 10(3), 326-338.

Boretsky, A.V., Zhetpisov, S.K. (2013). Human Trafficking: Issues of Investigation Techniques. World Applied Sciences Journal, 23 (1), 13-17.

Code of Criminal Procedure of the Republic of Kazakhstan. (1997). Adopted on December 13, 1997. [Online] Available: http://online.zakon.kz/Document/?doc_id=1008442 (July, 2014).

Elenyuk, G.A. (2001). Issues Resolved with forensic examination. Pavlodar: NKJI KazSLU.

Ginzburg, A.Ya., Povreznyuk, G.I., Salaev, B.A. (1998). Criminalistic methods and means of identifying the person. Almaty. Ayan Edet. Instruction on the procedure of forensic examinations conducting at the Kazakh Research Institute of forensic examinations. (1981). Alma-Ata. Kazakh Research Institute of the FE.

Investigator's directory. Applied Criminology: preparation and appointment of forensic examinations. (1992). Moscow. Russian Law, 3 , 139-140.

Laycock, G. (2004). New challenges for law enforcement. Springer Netherlands, 55-67.

McCartney, C. (2013). Forensic Identification Criminal Justice. Routledge.

Nickell, J., Fischer, J.F. (2014). Crime science: methods of forensic detection. University Press of Kentucky.

Pepper, I. (2010). Crime Scene Investigation: Methods And Procedures: Methods and Procedures. McGraw-Hill International. Roux, C., Crispino, F., Ribaux, O. (2012). From Forensics to Forensic Science. Current Issues in Criminal Justice, 24(1), 7-24. Teaching aid for appointing examinations. (2003). Astana. TMU SD MIA RK.

Tilley, N., Ford, A. (1996). Forensic science and crime investigation (Vol. 73). London. Home Office. Police Research Group. 